\title{
Innovations
}

\section{Art therapy for grief and self-care in medical settings}

\author{
November 17-18, 2018 \\ Doha, Qatar
}

Medical Humanities in the Middle East Conference

\section{Authors}

Natalia Gómez-Carlier; Sara Powell ${ }^{1}$

\section{Abstract}

Being a caregiver can be an emotionally

challenging and stressful job. Doctors, nurses, hospital staff and families are often burdened by the depletion of internal and external resources as they take care of others. In many cases burnout is related to unprocessed grief and lack of awareness of the importance of self-care., ${ }^{1,2}$

Grief is understood as the various emotional, physiological, cognitive, and behavioral reactions to loss; it follows a similar process in which people endure a period of sorrow, numbness, and even guilt or anger, followed by a gradual fading of these feelings as the person accepts the loss and moves forward.' It appears that grief resembles a movement from life, into death and back to life again. But, each experience of grief is unique and although there are models that attempt to guide us, there is at the moment no theory that can completely account for the way in which people cope with loss. ${ }^{3}$ Grief in medical settings has shown to be even more complicated as it is often postponed and/or repressed and shows a fluctuation between the experiencing of the grief and the avoidance of the grief. ${ }^{4}$ Additionally, there are various ways in which loss is experienced by health professionals; these experiences include loss of a close relationship with a patient; loss due to a professional's identification with the pain of family members; loss of one's unmet goals and expectations and one's professional self - image and role; losses related to one's personal system of beliefs and assumptions about life; unresolved losses or anticipated future losses; and the fear of the death of the self. ${ }^{5}$ To further complicate the process, grieving in health settings requires an acknowledgement that the whole system is experiencing grief simultaneously, making the collective culture a determinant player in how the grief can be processed. ${ }^{6}$
'ATIC Psychological and Counselling Center, Dubai, UAE

*Email: natalia@aticarttherapy.com

\author{
Cite this article as: \\ Gómez-Carlier N, Powell, S.. Art therapy for grief and self- \\ care in medical settings. In: Weber AS, Verjee MA, editors. \\ Proceedings of the 1st International Conference on Medical \\ Humanities in the Middle East [Internet]; 2018 Nov 17-18: Doha, \\ Qatar: Innovations in Global Health Professions Education; \\ 2019 March. p. 36-38. (Innovations in Global Health Professions \\ Education; vol. 2019, spec. no.: 1). https://dx.doi.org/10.20421/ \\ ighpe2019.01.12 \\ This is an open access article distributed under the terms of \\ the Creative Commons Attribution license CC BY 4.0, which \\ permits unrestricted use, distribution and reproduction in any \\ medium, provided the original work is properly cited.
}


How healthcare professionals manage their grief has become an important area of research as grief can lead to burn out which affects health

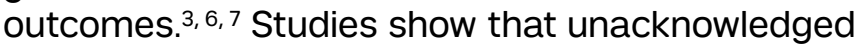
grief can affect treatment decisions, cause distraction, inattentiveness, impatience, irritability, emotional exhaustion and burnout.' To address this burnout, it becomes necessary to generate avenues to support and develop self-care protocols and practices so that health professionals can identify the needs present during grief which include: rest, relaxation, nourishment, a sense of security, trust, hope in the future and humour. ${ }^{8}$ Another aspect that needs to be highlighted is the importance of the persistence of hope through the suffering of grief, and how the experience of hope can increase confidence in physicians. ${ }^{9}$

Art therapy possesses unique characteristics that facilitate grief work as it serves a dual-purpose during grief: it firstly provides a way to alleviate and contain feelings of fear, crisis and threat while at the same time it honours the experience or the person that was lost.10 The focus is on doing rather than talking which helps alleviate the stigma; through art therapy caregivers develop the ability to explore a different way to connect to others and to their own inner world, improving self-awareness and decision making ${ }^{10}$. Art can also be a vehicle that reshapes grief, a way to transition loss and fear into hope and possibility helping in the creation of meaning, ${ }^{11}$ the rebalancing of the brain and the re-construction of attachments. ${ }^{12}$ Ultimately, in art therapy we have the opportunity to recognize and value the transpersonal aspects of art making in the time of mourning and to acknowledge important cultural factors that aid in the processing of the grief. ${ }^{13,14}$ Finally, in terms of self-care, art therapy provides a new language to safely express worry and creatively release stress; and self-care is an ethical responsibility health professionals have with their clients and with themselves. ${ }^{15}$

\section{Conflicts of interest: None.}

Funding sources: None.

\section{References}

1. Granek L, Krzyzanowska MK, Tozer R, Mazzotta P. Difficult patient loss and physician culture for oncologists grieving patient loss. J Palliat Med. 2012 Nov;15(11):125460. doi:10.1089/jpm.2012.0245

2. Abdulghani HM, AlKanhal AA, Mahmoud ES, Ponnamperuma GG, Alfaris EA. Stress and its effects on medical students: a crosssectional study at a college of medicine in Saudi Arabia. J Health Popul Nutr [Internet]. 2011 Oct [cited 2018 Nov 18]; 29(5):516-22. Available from: https://www.ncbi.nlm.nih.gov/ pmc/articles/PMC3225114/

3. Howarth R. Concepts and controversies in grief and loss. J Ment Health Couns. 2011 Jan;33(1):4-10. doi:10.17744/ mehc.33.1.900m56162888u737

4. Zisook S, Shear K. Grief and bereavement: what psychiatrists need to know. World Psychiatry. 2009 Jun;8(2):67-74. doi:10.1002/j.2051-5545.2009.tb00217.x

5. Papadatou D. A proposed model of health professionals' grieving process. Omega (Westport) [Internet]. 2000 [cited 2018 Nov 18]; 41(1):59-77. Available from: https://journals. sagepub.com/doi/10.2190/TV6M-8YNA-5DYW3CIE doi:10.2190/TV6M-8YNA-5DYW-3C1E

6. Sansone RA, Sansone LA. Physician grief with patient death. Innov Clin Neurosci. 2012 Apr;9(4):22-6.

7. Pantilat $\mathrm{SZ}$, Isaac M. End-of-life care for the hospitalized patient. Med Clin North Am. 2008 Mar;92(2):349-70, viii-ix. doi:10.1016/j. mcna.2007.11.001

8. LoboPrabhu SM, Molinari V, Lomax JW. Supporting the caregiver in dementia: a guide for health care professionals. Baltimore, MD: Johns Hopkins University Press; 2006. 295 p.

9. Kübler-Ross E. On grief and grieving: finding the meaning of grief through the five stages of loss. New York, NY: Scribner; 2005. 235 p.

10. Malchiodi CA. Art and loss. Art Ther (Alex). 1992;9(3):114-118. doi:10.1080/07421656.1992.10 758946 
11. Graham-Pole J, Lander D. Metaphors of loss and transition: an appreciative inquiry. Arts Health. 2009 Feb 25;1(1):74-88. doi:10.1080/17533010802527977

12. Kapitan L. Introduction to the neurobiology of art therapy: evidence based, complex, and influential. Art Ther (Alex). 2014;31(2):50-51. doi :10.1080/07421656.2014.911027

13. McNiff S. Art as medicine: creating a therapy of the imagination. Boston, MA: Shambala; 1992. $235 \mathrm{p}$.

14. Parisian K. Identity formation: art therapy and an adolescent's search for self and belonging. Art Ther (Alex). 2015 Jul;32(3):130-135. doi: $10.1080 / 07421656.2015 .1061257$

15. Wise EH, Hersh MA, Gibson CM. Ethics, self-care and well-being for psychologists: reenvisioning the stress-distress continuum. Prof Psychol Res Pr. 2012;43(5):487-494. doi:10.1037/a0029446

\section{About the authors}

Natalia Gómez-Carlier, MAAT, is an ATR-BC Psychologist with a Master's Degree in Art Therapy from the School of the Art Institute of Chicago. Founder of the Colombian Art Therapy Association, she has taught University level courses and has more than 20 years of clinical experience providing culturally sensitive interventions in Bogota, Chicago, New York, Muscat and Dubai.

Sara Powell, MA, is from the UK and is the founder of ATIC, an art therapy practice in Dubai, UAE. She has an MA in Art Therapy from LASALLE University, Singapore. Sara has over 9 years' experience and worked on numerous projects in collaboration with Government in Singapore and the GCC. She specializes in women's issues, and child and adolescent related disorders. 